\title{
Evolution of corrosion parameters in a buried pilot nuclear waste container in el Cabril
}

\author{
Carmen Andrade ${ }^{1}$, Samuel Briz ${ }^{1}$, Javier Sanchez ${ }^{1}$, Pablo Zuloaga ${ }^{2}$, Mariano Navarro ${ }^{2}$ and \\ Manuel Ordoñez ${ }^{2}$ \\ ${ }^{1}$ Institute of Construction Science "Eduardo Torroja" (IETcc), CSIC, \\ Serrano Galvache 4, 28033, Madrid, Spain. \\ ${ }^{2}$ ENRESA (Spanish Agency for Management of Radioactive Wastes) \\ Emilio Vargas, 7, 28043, Madrid, Spain.
}

\begin{abstract}
Modern concrete has a record of good performance of around 120 years although there are structures in perfect conservation made with roman concrete (mixture of lime and natural pozzolans). El Cabril repository has a design life of 300-500 years and therefore, it should keep its integrity much longer than the back experience we have on reinforced concrete structures, which makes necessary a closer monitoring with time on the aging of concrete in real conditions. With this purpose, Enresa has designed in collaboration with IETcc and Geocisa the installation of permanent sensors in a pilot nuclear waste container in buried conditions. The sensors were installed in 1995 for monitoring corrosion parameters and have been working until present. The non-destructive tests (NDT) applied are based in electrochemical measurements (corrosion rate, corrosion potential, electrical resistivity, concrete strains, oxygen availability). Relations between the climatic influence, the buried depth and the corrosion parameters are also presented. The results indicate that the temperature is a very relevant variable influencing the measurements because of the seasonal changes produced which makes all the other parameters to evolve accordingly. Values of activation energies of the resistivity changes are given although it seems more adequate to model the evolution with time by simply plotting the values registered at $20 \pm$ $2{ }^{\circ} \mathrm{C}$.
\end{abstract}

\section{INTRODUCTION}

El Cabril repository has a design life of 300-500 years with three main periods: i) operational during the construction, ii) surveillance where a minimum of monitoring is considered and iii) the post-surveillance where no more control is expected. The main cement based materials used as engineer barrier in the repository of El Cabril for low and medium radioactive wastes are the Cells, the Containers and the mortar filling the gaps between the drums introduced in the containers. Cells and containers are made of the same concrete composition while the mortar was specifically designed to be pumpable and with high impermeability (between $10^{-17}$ and $10^{-18} \mathrm{~m}^{2}$ ). The possible aggressions that the cement based materials can suffer during these periods have been identified to be: carbonation (during the operation only), water permeation (leaching) and reinforcement corrosion. More unlikely might be the bio-attack. Chlorides are not in the environment but they are inside the drums as part of analytical wastes. The description of the installations has been made before [1].

The design life of 300-500 years is longer than the existing experience on this kind of structures because the oldest structures in reinforced concrete were built about 120-150 years 
ago. Much older concretes have arrived to present, but they are unreinforced with steel and based in mixes of lime and pozzolan which result a not enough close analogue to modern cements. In addition the concrete in El Cabril will be at the atmosphere until it will be covered by the ground. In order to gain experience on this buried conditions a pilot container was built in 1994 and was instrumented with corrosion sensors (figure 1). In present paper the results registered from the beginning are shown and, due the strong relative influence of temperature, an attempt to start to model the evolution with time is made by calculating the "apparent Activation Energy" of the different parameters measured. Only the case of the Resistivity is mentioned in present paper.
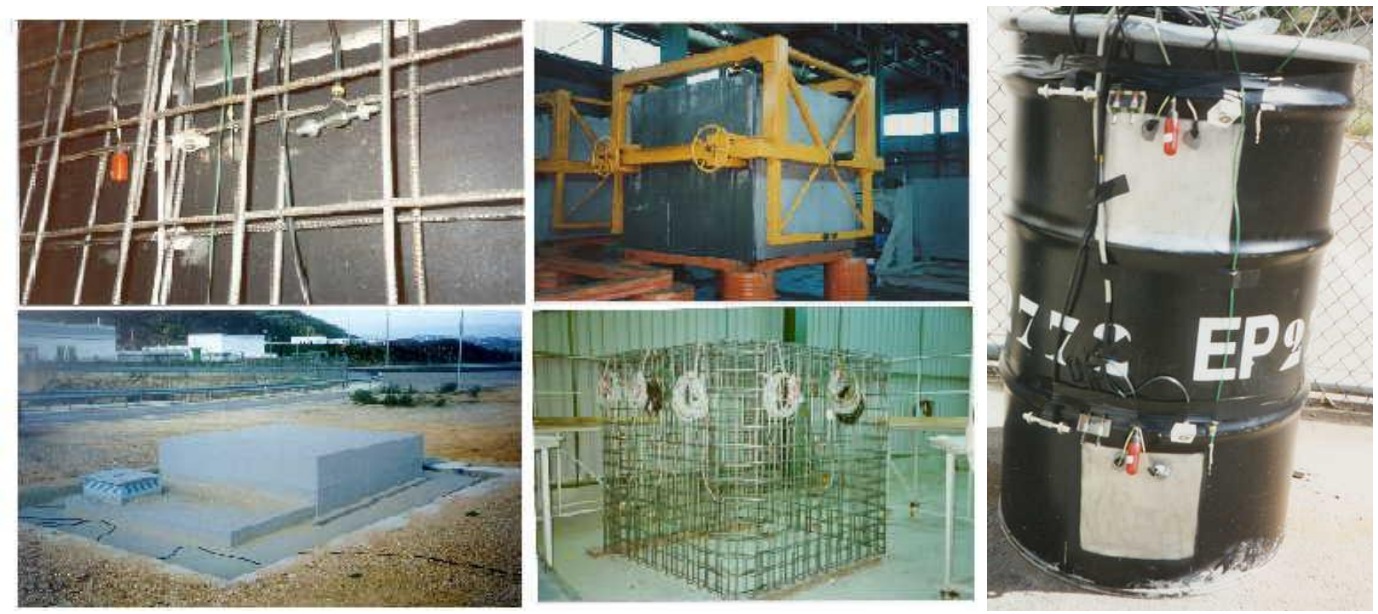

Figure 1. Left: sensors attached to the reinforcement and the aspect of the buried container. Middle: the container being moved after fabrication and the sensors placed in the three levels of reinforcing. Right: instrumented drum before being placed inside the container.

\section{DESCRIPTION OF PILOT CONTAINER AND ITS INSTRUMENTATION}

The containers are prefabricated in a specially devoted plant. Several views of it and its instrumentation are shown in figure 1. The reinforcements are placed in the modules and then, concrete is cast by robotic means, to be finally steam cured with temperatures lower than $60^{\circ} \mathrm{C}$. Characteristic strengths between 50-60 MPa are typically achieved at 28 days. For the sake of the test 6 drums, also shown in figure 1, were introduced in the container and the spaces filled with the "filling mortar" [1].

This pilot container has been fabricated in 1994 and instrumented by embedding 27 sets of electrodes (figure 2). The container was buried leaving aside a chamber where the corrosion data logger (Geologger measurement system) and a reference probe were placed besides the container. All the details were described in a previous paper [2]. 

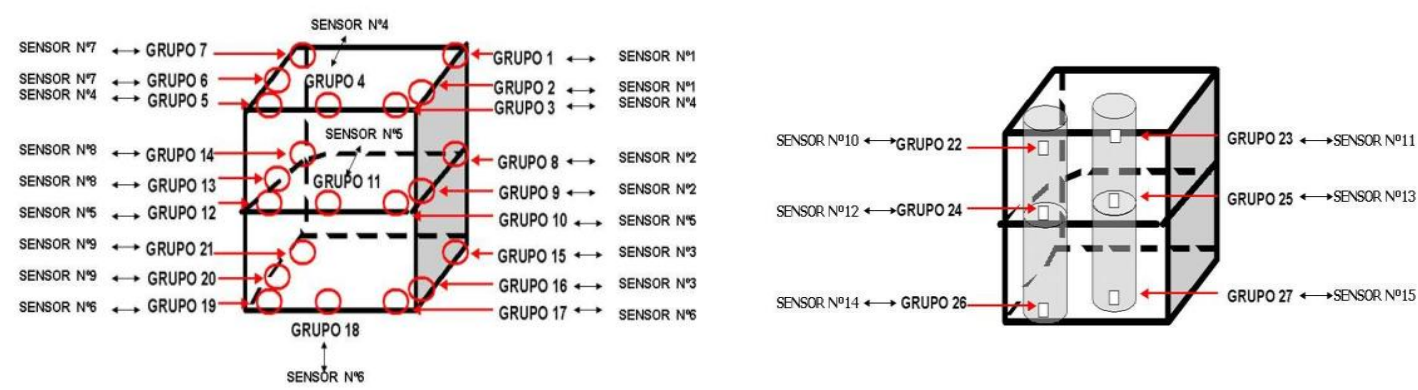

Figure 2. Position of the sensors in the container and in the drums.

\section{$\underline{\text { Instrumentation and Sensors }}$}

The Geologger potentiostat has 50 available channels. The parameters controlled are: temperature, concrete deformation, corrosion potential, resistivity, oxygen availability and corrosion rate. The impact of temperature on several of the parameters is remarkable, and therefore, care has to be taken when interpreting on-site results. Some of the sensors embedded are shown in figure 3 .
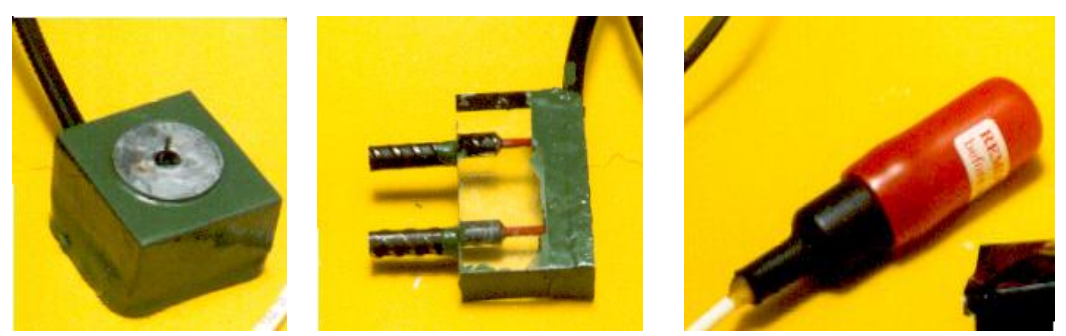

Figure 3. Electrochemical sensors embedded in the buried container. Left: sensor for corrosion rate and resistivity. Middle: sensor for resistivity (additional method). Right: sensor for corrosion potential with its cap.

For measuring the corrosion potential and the corrosion rate, direct metallic contact was made to the main rebar of the container or by erasing the surface of the drum. The rebar and the drum were made to act as working electrodes. In order to obtain the real value of the corrosion rate, the measurement method used was the Polarization Resistance [3, 4]. However, as the surface of the working electrode is bigger than the counter (small disk) a technique based in the measurement of the slope of the transient pulse after application of a step of current, has been used. This technique is not so accurate as that in which the "sensorized guard ring" is based [5, 6]. However, as the technique is continuously recorded, any scatter or wrong measurement can be easily identified. On the other hand, it has the advantage of being very quick, and it allows a very small disturbance of the system. Obviously, a method based in the use of a guard ring around the small counter disk entails great difficulties in order to operate embedded in the concrete. Therefore, an alternative methodology had to be used in spite to lose accuracy.

Regarding the resistivity [7], it is measured by means of the current interruption method from a galvanostatic pulse. The oxygen flow at the rebar level is measured by applying a cathodic constant potential of about $-750 \mathrm{mV}(\mathrm{SCE})$ and measuring the current of reduction of oxygen [8]. 


\section{RESULTS}

From the 27 groups of sensors installed, only less than $10 \%$ of them failed. The rest show a good response even ten years after its installation. As an example, figure 4 shows the temperature values from end 1994 for all the sensors embedded in the container. From the figure is possible to deduce that the temperature evolves due to the seasonal changes. Figure 5 gives the maximum, minimum and averaged values of certain groups placed in the top, medium and lower levels of the pilot container and that embedded in the reference specimen placed in the chamber that contains the Geologger besides the container.

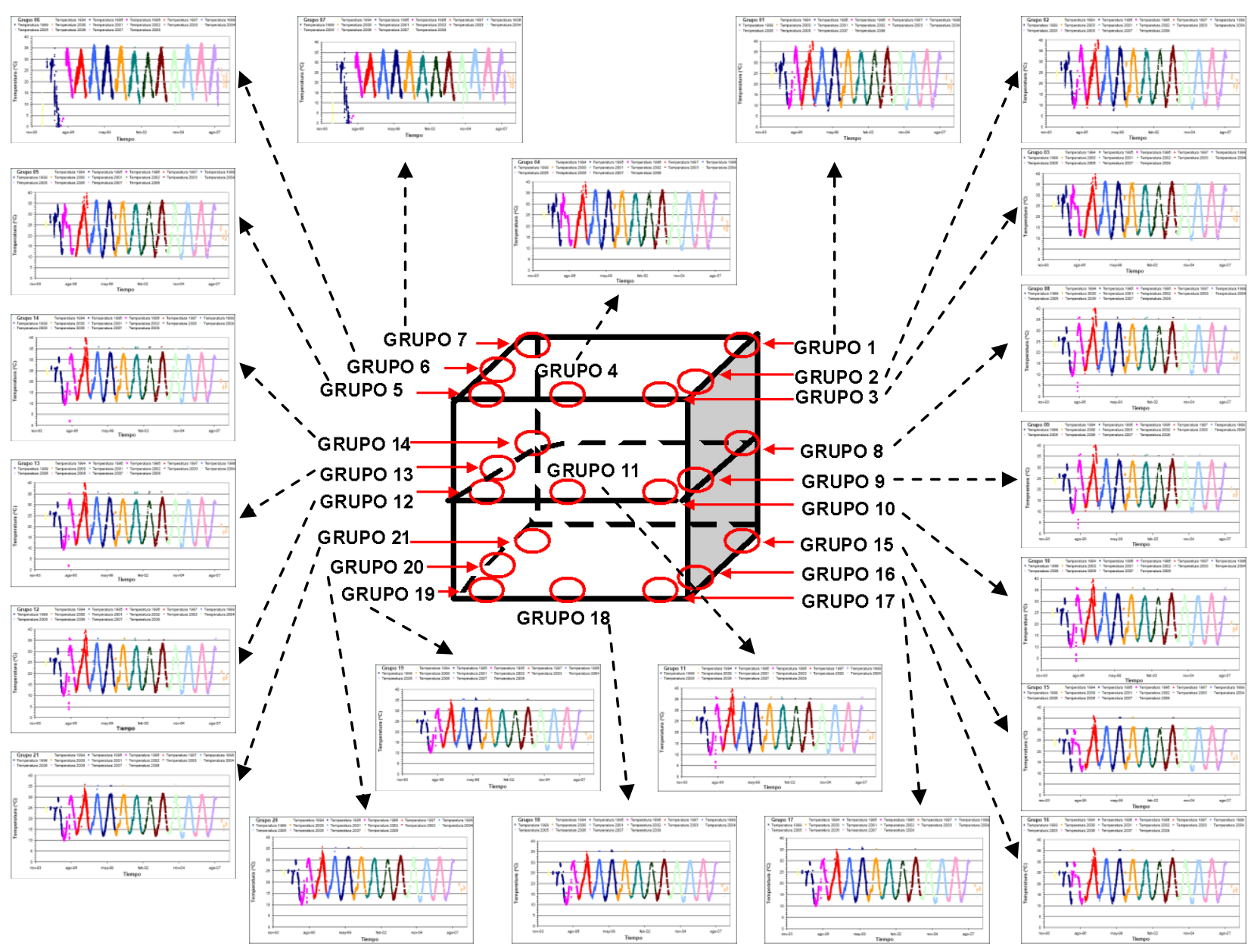

Figure 4. Evolution with time of temperature in all the sensors embedded in the pilot container. 

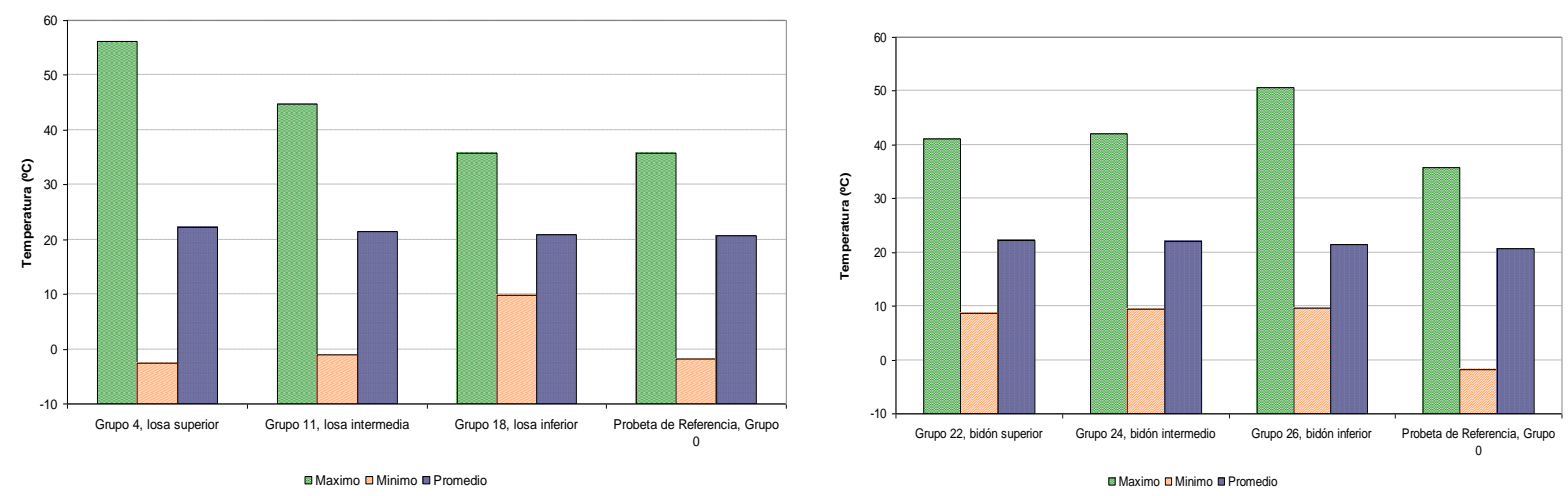

Figure 5. Maximum, minimum and averaged temperature in the three levels and the reference specimen placed in the chamber besides the container. Left: in the container. Right: in the drums.

These records indicate that, although the average values are similar in all levels, the maximum temperature is much higher in the top part reaching around $50^{\circ} \mathrm{C}$ while in the lower level the maximum is around $35^{\circ} \mathrm{C}$. This behaviour is not shown however by the drums where the maximum temperatures do not show the same trend with the depth because, roughly, they are similar in the three levels.

Figure 6 shows the evolution of micro-strains and of oxygen availability. The microstrains show initially the sharp shrinkage produced and its slower increase with time. The values will enable the modelling and prediction in time of this phenomenon that seems not to stop completely.
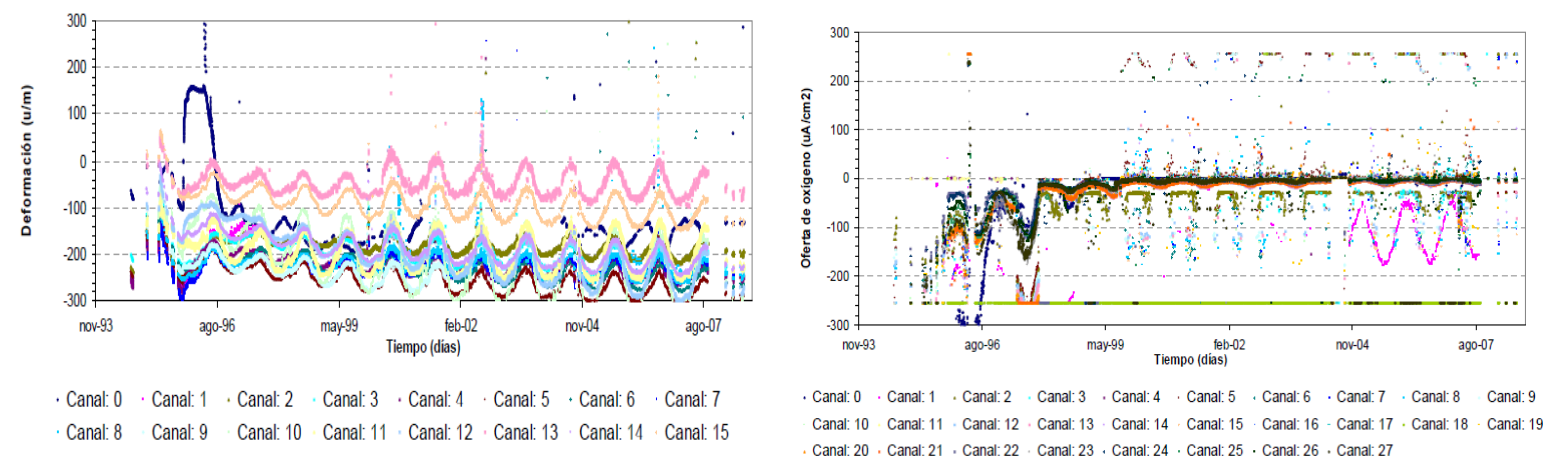

Figure 6. Evolution with time. Left: micro-strains. Right: oxygen availability.

Regarding the oxygen evolution, it also suffers and abrupt change during the first years of recording as it is relatively high at the beginning while the cathodic current is zero or even positive later. This behaviour is not clear as it would represent that an anaerobic ambient is being produced. It can be however analysed together the values of corrosion potential and resistivity. The corrosion potential evolves slowly but steadily towards more positive values indicating that a lack of oxygen is not being produced (figure 7). The trend of the oxygen then may be justified with the increasing of the resistivity which can indicate and continuous decrease in the amount of liquid water in the pores, likely due to the progressive hydration. The lack of electrolyte would justify the values almost zero or positive of the oxygen availability. However this hypothesis has to be confirmed in the future where several different humidity conditions will be applied to the container in order to progress in the understanding. 

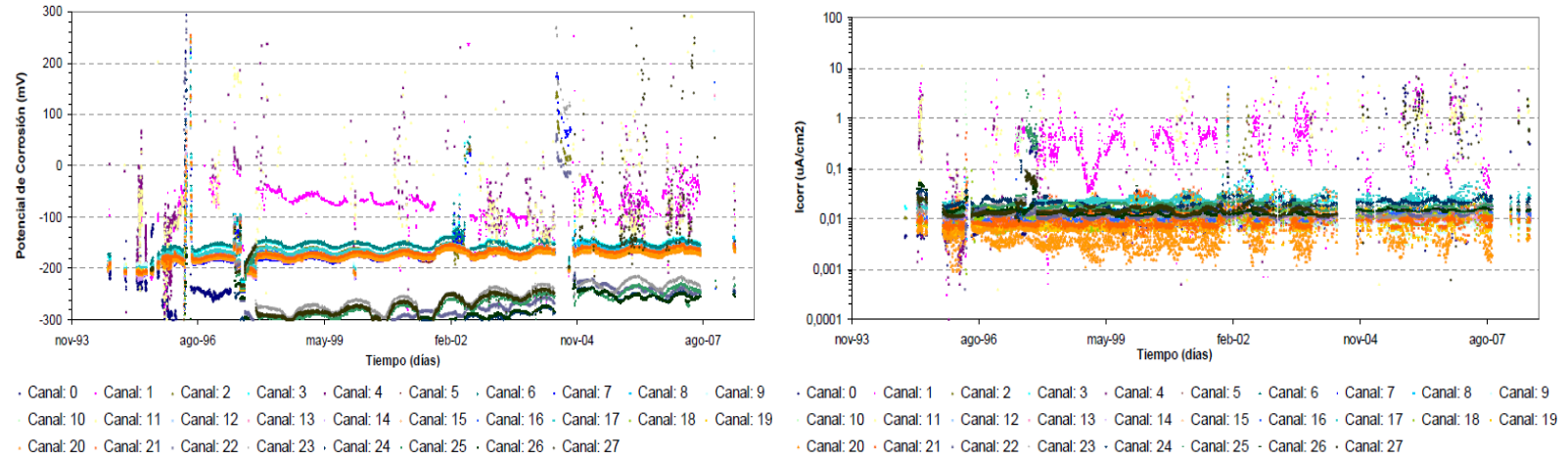

Figure 7. Evolution with time. Corrosion Potential. Right: Corrosion rate.

As mentioned before the corrosion potential almost does not change although a slow progression towards more positive values is clear (figure 7). What is more interesting is to verify that the corrosion potential is different (more positive for around $100-150 \mathrm{mV}$ ) in the reinforcement embedded in the container than that of the steel of the drum embedded in the filling mortar. With respect to the corrosion rate, the values below $0.1 \mu \mathrm{A} / \mathrm{cm}^{2}$ indicate a perfect passivity of the steel. It is worth noting however that the temperature seasonal cycles can be well identified in both the corrosion potential and rate.

Finally, regarding the resistivity, it increases with time and show the effect of the seasonal evolution of temperature in a higher proportion and the time progresses (figure $8 \mathrm{Left}$ ). This has to be analysed together with the previous appreciation of the progressive hydration and then it would imply that a drier concrete will show more pronounced resistivity changes due to temperature than a more humid concrete. The increase with time of the resistivity is better appreciated in figure 8-Right, where the evolution of the resistivity values at $20 \pm 2{ }^{\circ} \mathrm{C}$ is plotted. This graph reveals that at the beginning the evolution is exponential but later a straight line can be plotted.
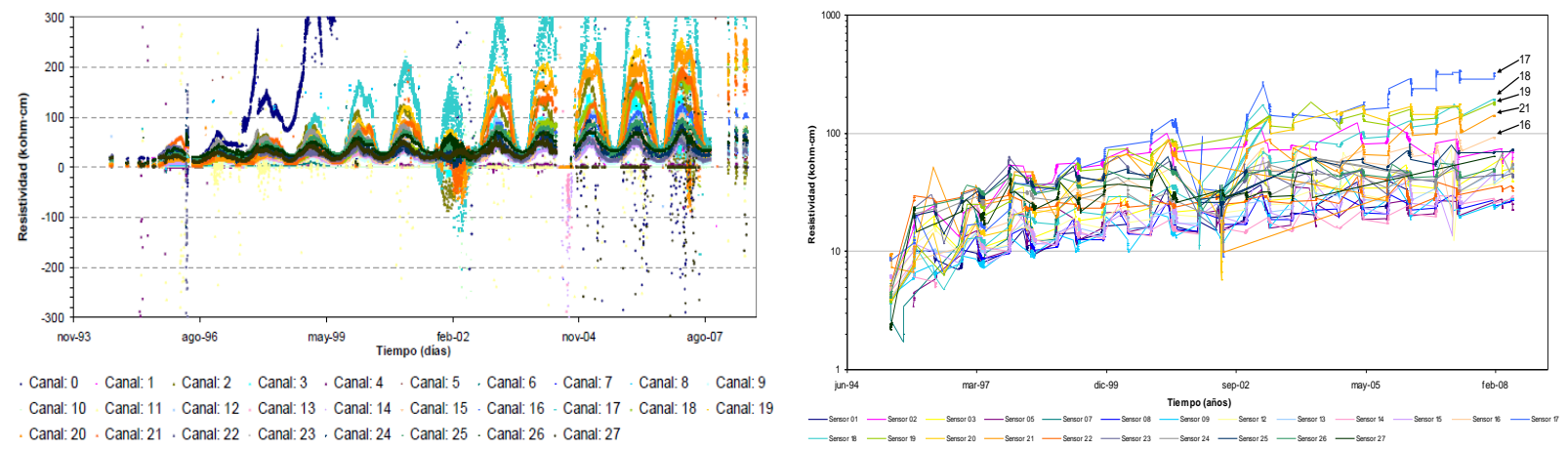

Figure 8. Evolution with time of Resistivity. Left: all values, and right: values between 18 and $22{ }^{\circ} \mathrm{C}$. 


\section{DISCUSSION}

The results recorded should provide useful of information to be incorporated in future models for performance prediction. At this respect, it has to be reminded that none of the existing models for predicting corrosion of reinforcements have been validated during enough long time. The existing models [9-12] are of different nature: empirical, analytical or numerical. In general all of them are based in considering diffusion as the main mechanism of transport of carbon dioxide and chlorides. Very scarce is the number of models considering water absorption in addition to diffusion [12]. For the sake of present results, what we like to study is the effect of temperature in the evolution of the different parameters measured and also its effect on possible dimensional changes (shrinkage). Only the preliminary analysis if the resistivity is made in present paper.

In figure 9 the representation of the resistivity versus the temperature is made. From the plot it can be calculated an "apparent Activation Energy": $\mathrm{A}=\mathrm{A}_{0} \mathrm{e}^{(-\mathrm{Ea} / \mathrm{R} \cdot \mathrm{T})}$. From the figure it is very interesting noting that at $20^{\circ} \mathrm{C}$ it is produced a significant change in the slopes. All of them are shown in table 1 . Below $20^{\circ} \mathrm{C}$ the slopes do not change very much, although the evolve because the increase in the resistivity with the age. However above $20^{\circ} \mathrm{C}$ the slopes change very significantly with time. It might be deduced that as the concrete is drier with time, the change in resistivity is more pronounced with temperature. This trend can be related to the oxygen availability and calls for further testing by producing artificially different humidity states in the container in order to verify the hypothesis.



1994
1995
1996
1997
1998
1999
2000
2001
2002
2003
2004
2005
2006
2007
2008

Figure 9. Resistivity values of group 3 sensors versus temperature that allows to calculate the Activation Energy. 
Table 1. Apparent Activation Energies, $\mathrm{E}_{\mathrm{ap}}$, of the different slopes shown in figure 9.

\begin{tabular}{|c|c|c|c|c|}
\hline № & $\begin{array}{c}\text { Eap }>20 \text { ㅇ } \\
(\mathrm{J} / \mathrm{mol})\end{array}$ & $\begin{array}{c}\text { Eap }<20^{\circ} \mathrm{C} \\
(\mathrm{J} / \mathrm{mol})\end{array}$ & $\begin{array}{c}\text { Average } \\
\text { R2 Eap } \\
\mathbf{2 0}\end{array}$ & $\begin{array}{c}\text { Average } \\
\text { R2 Eap } \\
\mathbf{2 0}\end{array}$ \\
\hline 1 & 31390,291 & 59968,961 & 0,888 & 0,793 \\
\hline 2 & 78552,776 & 50004,315 & 0,899 & 0,881 \\
\hline 3 & 37777,635 & 87358,217 & 0,949 & 0,904 \\
\hline 4 & & & & \\
\hline 5 & 39477,362 & 57462,029 & 0,929 & 0,941 \\
\hline 6 & & & & \\
\hline 7 & 35355,421 & 77513,328 & 0,674 & 0,814 \\
\hline 8 & 30245,416 & 82646,018 & 0,972 & 0,927 \\
\hline 9 & 34475,459 & 30095,728 & 0,854 & 0,765 \\
\hline 10 & & & & \\
\hline 11 & & & & 0,967 \\
\hline 12 & 38524,552 & 90782,394 & 0,957 & 0,962 \\
\hline 13 & 40306,981 & 44634,395 & 0,912 & 0,870 \\
\hline 14 & 33450,406 & 56639,846 & 0,925 & 0,894 \\
\hline 15 & 39921,175 & 96788,769 & 0,889 & 0,885 \\
\hline 16 & 76736,424 & 40940,460 & 0,961 & 0,921 \\
\hline 17 & 129828,817 & 70651,644 & 0,946 & 0,906 \\
\hline 18 & 58528,728 & 42445,518 & 0,932 & 0,895 \\
\hline 19 & 133026,563 & 56083,054 & 0,955 & 0,958 \\
\hline 20 & 126592,825 & 37470,356 & 0,965 & 0,879 \\
\hline 21 & 91492,450 & 44405,932 & 0,967 & 0,952 \\
\hline 22 & 39073,778 & 36962,698 & 0,962 & 0,870 \\
\hline 23 & 29862,174 & 33838,515 & 0,928 & 0,857 \\
\hline 24 & 24734,584 & 25095,363 & 0,704 & 0,793 \\
\hline 25 & 30407,063 & 29919,905 & 0,816 & 0,831 \\
\hline 26 & 27238,966 & 38195,922 & 0,932 & 0,929 \\
\hline 27 & 37917,152 & 32925,933 & 0,502 & 0,439 \\
\hline Average & 54126,826 & 53166,491 & 0,888 & 0,864 \\
\hline Average & 53646,659 & 53646,659 & 0,876 & 0,875 \\
\hline total & & & & \\
\hline & & & & \\
\hline
\end{tabular}

If it is correct that would mean that the concrete would continue to hydrate with time at expenses of the pore solution and then, it will dry in spite of being buried. This drying will have an impact in the shrinkage, the resistivity and the oxygen to be reduced at cathodic potentials. These facts should be incorporated into the models of service life.

With respect to the values of the slopes or Apparent Activation Energies, it has to be commented by looking at table 1 , that the values are very high as the sensors embedded in the container show average values higher than $53.646 \mathrm{~kJ} / \mathrm{mol}$ for temperatures higher than $20^{\circ} \mathrm{C}$ while the normal in electrolytes is to show values around $20 \mathrm{~kJ} / \mathrm{mol}$ and other authors $[13,14]$ have measured this range of values, which only are recorded here in the drums.

\section{CONCLUSIONS}

The establishment of a suitable model of service life of cementitious materials used in repositories of radioactive wastes has the main difficulty of the lack of proper calibration of existing models and their use for much shorter service lives. In addition, there are still important items to be measured and collected as they are the characterization of the environment and for the correct identification of key parameters involved in long term durability.

The results of several corrosion sensors embedded in a pilot container from 1994 indicate that: 
1. The temperature in the concrete changes according to seasonal variations and the buried depth attenuates the extreme changes.

2. All the parameters evolve according these seasonal changes which facilitates the analysis through the calculation by means of an "apparent activation energy", $\mathrm{E}_{\mathrm{ap}}$.

3. The $\mathrm{E}_{\mathrm{ap}}$ are in general around and much above $20 \mathrm{~kJ} / \mathrm{mol}$.

4. The resistivity shows a marked change of regime with temperature, below and above $20^{\circ} \mathrm{C}$, being the changes more pronounced above that temperature.

5. The evolution with time can be modelled by simply plotting the values registered at $20 \pm 2{ }^{\circ} \mathrm{C}$.

\section{ACKNOWLEDGMENTS}

Recognition is made to the funding provided by ENRESA to support the investigation. The authors would like to acknowledge the financing of the Ministry of Science and Innovation for the INGENIO 2010-CONSOLIDER Project on "Safety and Durability of Structures: SEDUREC" and BIA2010-18863.

\section{REFERENCES}

1. Begin typing text here.

1. C. Andrade, I. Martinez, M. Castellote, and P. Zuloaga, "Some principles of service life calculation of reinforcements and in situ corrosion monitoring by sensors in the radioactive waste containers of El Cabril disposal (Spain)," Journal of Nuclear Materials, vol. 358, pp. 82-95, Nov 2006.

2. C. Andrade, J. Rodriguez, F. Jimenez, J. Palacio, and P. Zuloaga, "Embedded sensors for concrete structures instrumentation," in OECD-NEA Workshop on Instrumentation and Monitoring of Concrete Structures Brussels, ed Belgium, 2000.

3. C. Andrade and C. Alonso, "Test methods for on-site corrosion rate measurement of steel reinforcement in concrete by means of the polarization resistance method," Materials and Structures, vol. 37, pp. 623-643, 2004.

4. C. Andrade, C. Alonso, J. Gulikers, R. Polder, R. Cigna, O. Vennesland, et al., "Test methods for on-site corrosion rate measurement of steel reinforcement in concrete by means of the polarization resistance method," Materials and Structures, vol. 37, pp. 623643, Nov 2004.

5. C. Andrade, J. Sanchez, J. Fullea, N. Rebolledo, and F. Tavares, "On-site corrosion rate measurements: 3D simulation and representative values," Materials and Corrosion, vol. 63, pp. 1154-1164, 2012.

6. C. Andrade and J. A. González, "Quantitative measurements of corrosion rate of reinforcing steels embedded in concrete using polarization resistance measurements," Materials and Corrosion, vol. 29, pp. 515-519, 1978.

7. K. R. Gowers and S. G. Millard, "Measurement of concrete resistivity for assessment of corrosion severity of steel using Wenner technique," Aci Materials Journal, vol. 96, pp. 536-541, 1999. 
8. O. E. Gjorv, O. Vennesland, and A. H. S. Elbusaidy, "Diffusion of dissolved-oxygen through concrete," Materials Performance, vol. 25, pp. 39-44, Dec 1986.

9. D. J. Naus, M. W. Johnston, C. Andrade, H. Ashar, Z. Bittnar, H. Breulet, et al., "RILEM TC 160-MLN: Methodology for life prediction of concrete structures in nuclear power plants - Progress report - August 1999," Materials and Structures, vol. 33, pp. 98-100, Mar 2000.

10. J. R. Clifton, "Predicting the service life of concrete," Aci Materials Journal, vol. 90, pp. 611-617, Nov-Dec 1993.

11. J. Rodriguez, L. M. Ortega, J. Aragoncillo, D. Izquierdo, and C. Andrade, Structural assessment methodology for residual life calculation of concrete structures affected by reinforcement corrosion vol. 16, 2000.

12. P. Zuloaga, M. Ordonez, C. Andrade, and M. Castellote, "Ageing management program for the Spanish low and intermediate level waste disposal and spent fuel and high-level waste centralised storage facilities," in Amp 2010 - International Workshop on Ageing Management of Nuclear Power Plants and Waste Disposal Structures. vol. 12, V. Lhostis, K. Philipose, R. Gens, and C. Galle, Eds., ed, 2011.

13. M. Koster, J. Hannawald, and W. Brameshuber, "Simulation of water permeability and water vapor diffusion through hardened cement paste," Computational mechanics, vol. 37, pp. 163-172, 2006.

14. M. Raupach, "Results from laboratory tests and evaluation of literature on the influence of temperature on reinforcement corrosion," in Corrosion of Reinforcement in Concrete: Monitoring, Prevention and Rehabilitation, J. Mietz, B. Elsener, and R. Polder, Eds., ed, 1998, pp. 9-20. 